\title{
E-portfolios and relational space in the early education environment
}

\section{Aisling Gallagher}

Abstract: This paper considers the role of eportfolios as an online tool intended to foster greater engagement between parent, teacher and child in early education settings. Drawing on New Zealand based research, I will critically examine the introduction of this technology as more than an addition into already existing ECEC services. Rather, I will highlight the generative impact it has in facilitating new kinds of relations between parents, teachers and managers, within what I term an emergent 'virtual landscape of ECEC'. Ultimately I argue that this landscape is shaped by asymmetries of power, which allow for processes of subjectification and governing in ECEC to occur in new ways.

Keywords: eportfolios, relational space, ANT, virtual landscape of ECEC, governing.

\section{Introduction}

Its a sunny Tuesday afternoon and I am sitting in my office. An email pops up in the corner of my screen which immediately draws my attention. It's my daughter's daycare service, and a new learning story has just been added to her eportfolio. Keen to see what my two-year-old has been doing in the sunshine, I log in to see her smiling face as she runs around cooling off under a water sprinkler. I read about how she was immersed in making pretend muffins for her friend Isabella most of the morning. Heartened to see she is enjoying herself, quelling the perpetual pangs of guilt that my children are separated from me for most of their waking hours, I send a message in response about how much I enjoyed seeing her 'baking'. I wonder if her grandmother will see this 
story and also comment, as they made a cake recently together. I think about what I can do to encourage her new-found interest in making and sharing, before a knock on the door breaks me from this reverie.

I am but one of thousands of parents in New Zealand who are involved in their young children's learning experiences through eportfolios. The rise of online portfolios, as repositories of children's learning stories ${ }^{1}$ and platforms for engagement between teachers, children and parents, has been a marked change in the early education (ECEC) environment in the last ten years (Higgins \& Cherrington, 2017). In New Zealand, as in many other countries, online portfolios have become an increasingly popular way for educators to document and communicate children's learning to parents and in return for parents to respond (Goodman \& Cherrington, 2015; Lewis, 2015). Indeed, for parents like myself, online portfolios have become an invaluable way of being in touch with your child and their development during the working day. Moreover, the platform has the capacity to facilitate the involvement of wider family members, who may be located in far flung parts of the world and thus operating on asynchronous timeframes, to feel part of their learning journey too (Beaumont-Bates, 2017).

The introduction of eportfolios follows on from a broader proliferation of digital technology in the early education setting. This of course has not occurred without concerted debate in education and related disciplines over the last twenty years (Kerckaert, Vanderlinde \& van Braak, 2015; Plowman $\&$ Stephen, 2005). The development of more mobile, ubiquitous technologies (such as tablets and 'smart' devices of various kinds) have led to a flourishing of ICT in young children's lives more generally (Valentine \& Holloway, 2002). While the literature on eportfolios in early education is relatively new ${ }^{2}$ (Higgins \& Cherrington, 2017), a primary focus of this work has been to consider the potential benefits and disadvantages the integration of the technology may have in the early education setting (Lewis, 2015; Penman, 2014). To that extent, it has been argued that the increasingly interactive online environment offered through eportfolios has overall tended to be more conducive

1 A Learning Story is a record of what a child has been seen doing in an ECEC environment. It can be a paragraph or longer, and usually focusses on a specific snapshot of the childs learning over a particular period of time. Learning stories are written from the perspective of the adult who is interpreting what the child is doing. These narratives are usually written up after the event, during the teachers 'non-contact' time. However, there have been some criticisms of the use of learning stories in ECEC. See for example Blaiklock (2008).

2 Eportfolios have a much longer history of use in tertiary, secondary and primary education (see for example Jafari \& Kaufman 2006). 
to building relationships between teachers and the child's wider family unit. As Beaumont-Bates (2017) has documented, reliance on paper based means of communication led to minimal involvement and response by parents, in large part because of the time taken to engage and respond to the stories ${ }^{3}$. Indeed, as I will illustrate, digitally recording and documenting learning stories has allowed for new temporalities and spatialities of communication to emerge through the online platform. As suggested by my opening narrative, parents can receive and respond to stories at the desktop or via their phone in a more convenient and expeditious means than before. It is perhaps unsurprising then that research findings suggest that it has helped foster more supportive learning environments for the young child by bringing family and teachers closer together, and by reinforcing learning that parents can repeat at home. Justified by ECEC services through a discourse of efficiency in communication for both parents and teachers, the introduction of eportfolios across early education environments in NZ has therefore been surprisingly expeditious.

From another perspective however, it is perhaps no coincidence that eportfolio technology has flourished in the early learning environment at a point where more mothers than ever are entering the workforce (OECD, 2014). Indeed in many countries, like New Zealand, being an active participant of the workforce is increasingly seen as the basis on which your rights as a citizen are founded, and so women are openly encouraged to place their child in early education in lieu of being at home (MacLeavy, 2011; McDowell, 2004). Within this neoliberal politico-economic context, I argue that eportfolios can also be viewed as part of a suite of technologies that work to address the anxiety many parents feel when separated from their young children for most of their waking day. As suggested by my opening narrative, it offers a means of drawing parents closer to their young child(ren) and their daily experiences in a way paper based portfolios could not do. In an increasingly neoliberalised work environment, where a universal worker model takes priority over more traditional gendered divisions of labour (Lewis, 2001), technology like the eportfolio aims to overcome the 'friction of distance' of being separated from your child. In so doing, it serves to visibilise the day to day relations between parents, child and teacher in new ways, and through such visibility I argue can become a significant means through which new forms of governing and subjectification can occur in the ECEC space.

3 However, this is not an either or situation. Some early education providers continue to maintain the paper copy of the portfolio alongside the electronic one, so children can reflect back on their learning by looking through the paper based version (Penman, 2014). 
To further develop my interest in eporfolios, and in keeping with the aims of this special issue, I will draw on recent work in geography on networked, relational space, coupled with critical work on processes of governing (Rose, 1999; Lemke, 2002) to explore the potentially transformative impact of eportfolio technology on the subjects and spaces of ECEC ${ }^{4}$. Thinking about the ECEC environment as a closed discrete space into which the eportfolio technology is merely 'added' overlooks the centrality of this technology in shaping the experiences of ECEC for parents and teachers. To develop this alternative view of eportfolios I have foregrounded poststructural understandings of relational space as open-ended, dynamic and importantly involving both human and non-human actors in its constitution. In doing this I have positioned the eportfolio as a constituent part of an emergent 'virtual landscape of ECEC'. This landscape is not apolitical, but rather is shaped by undulating power relations and asymmetries which frame how parents and teachers engage in this learning and communicative space. Ultimately this paper will offer a critical examination of the normative work of subjectification which takes place through the technology in shaping the subjects and practices of the 'good' parent and the 'good' teacher. The discussion herein is empirically informed by exploratory interviews conducted with creators and developers of the two main online portfolio companies in New Zealand in 2014. Reinforcing this empirical work, I have drawn on my own position as a mother of two young children in an early education setting which uses eportfolios, to reflect on the experience as a parent-user of this technology.

\section{Rethinking Notions of Space, Flow, Distance and Proximity}

Debates in geography over the last twenty-five years have (re)turned to the ontological footing on which the idea of space is understood (Eldon, 2009; Murdoch, 2006). In doing so there has been a move in geography and the social sciences more generally beyond analysis of Euclidean or topographical understandings of space as an absolute, fixed container, in which life merely occurs. Rather, space has been understood as an increasingly subjective and processual emergence. Reimagined as the outcome of the interaction between different sets of relations, spaces are understood as multiplicities which are made of different spatial practices, identifications and forms of belonging (Crang \& Thrift, 2000; Massey, 2005; Murdoch, 2006). Through this poststructuralist lens, it is argued that objects exist in a system of re-

4 In this paper I have only considered parents and 'teacher' within the analysis. Further empirical work is necessary to consider the impact on children. 
lations to other objects, such that space itself is constituted through these interrelationships. As Harvey suggests, a particular space once formed is merely a 'permanance', where relations have only ever been temporarily stabilised (Harvey, 2006). Space therefore is always in the process of (re) creation, open-ended and never closed (Massey, 2005). There is a power geometry to this stabilisation, such that some relations are expressed as dominant and important, and others diminish out of existence (Allen, 2011). Working through this flattened and relational ontological lens, it follows that there are no essential qualities of any given place or object outside the relations you are situated in. Taken for granted ideas of local and global, or micro and macro are merely the outcome of the position occupied within the particular network relations you are embedded in ${ }^{5}$, rather than a predefined hierarchial power structure.

One way of understanding relational space is through the metaphor of the network. Within poststructural understandings of networked space both human and non-human actors are understood to have potential agency. As part of the broader relational turn in the social sciences, Actor Network Theory has emerged as a popular methodological approach which adopts this ontological perspective and allows us to trace networks of relations between human and non-human actors in the creation of socio-spatial phenomena (Latour, 2005; Law \& Hassard, 1999). Stemming from a broader critique of the impact of science and technology on society (Law, 2008), this approach focuses in particular on how actors are enrolled and how power flows through networks in particular ways. Stretching network relations outwards to bring new actors in is known as a process of translation. In this process, "the enrolled actor identifies with the network through a modification of the actor's identity or a modification of the network to encompass the actor" (Murdoch, 2006, p. 62). Thus those involved in the network are changed in some way through their involvement in network relations. Actors come with pre-existing identities, but all adapt and change to some extent to enter into the network. It is through this process that we can see how subjectification takes place through translation. In order for a network to be stabilised and to work, a degree of normalization has to take place such that behaviours and practices of those involved become regularized and in turn potentially governable. This is a two-way process, as modification of the actors identity is only one part, modification of the network itself to accommodate a new actor is also required. The stabilization of a network and the enrollment of

5 Although see the 'scale debate' in geography for further discussion (Marsden, Jones \& Woodward 2005). 
diverse actors into that network is only possible once actors different goals are aligned. The work of stabilization however, is often left to the non-human component of the network, as they make "good disciplinary machines" (Murdoch, 2006, p. 66).

Thinking through a more networked understanding of space, as espoused by ANT, has profoundly changed how geographers understand the constitution of social and material relations. One of the key outcomes of a relational ontology has been a questioning of the taken for granted assumptions of concepts like distance and proximity. As Murdoch suggests (2006, p. 87) "places with a similar set of elements and similar relations between them are close to one another and those with different elements or relations are far apart. Thus distance is a function of the relations between elements" (see also Mol \& Law, 1994). An example of this would be how we experience notions of proximity over and above physical closeness. I could feel closer to my colleagues in the UK through working on the same project together than my office neighbour who I only see sporadically. Rethinking distance and proximity as the outcome of more emotional and affective experiences, rather than solely physical locatedness, opens up alternative ways of exploring our perceptions of caring spaces like that of ECEC.

Building on this understanding of relational space, health geographers Christine Milligan and Janine Wiles (2010) extend it to reconceptualise the well utilised concept of 'landscapes of care'. In their work they seek to disrupt accepted notions of proximity in the delivery of care as being based solely on physical closeness. As they suggest "work on care has tended to overlook or underestimate the frequency, importance and quality of alternative forms of contact and proximity (for example, via telephone, email, webcam or videolink) and the ways in which advances in information and care technology are contributing to the folding or collapsing of the time-space continuum" (2010, p. 741). Other examples of care giving where this plays out is telemedicine and forms of remote monitoring technology (the St Johns alarm for the elderly for example). Drawing on their work on landscapes of care, I suggest that there is ground for a more indepth examination of the particular role of different technologies in facilitating care at a distance. I propose to explore this through what I call here a 'virtual landscape of ECEC'. My adaptation of Milligan and Wiles' work proposes to take into account care which is happening at asynchronous times (rather than solely in real time between participants via the technology). In such an analysis, the way the technology operates and the means through which it generates affective and emotional responses is an important aspect in caring for another in lieu of 
direct contact. I suggest that examining this process allows for new insights into the agency of the technology in forming and maintaining the relational network, in this case that which I call the virtual landscape of ECEC.

In the next section I will draw on the insights from ANT and relational space in two ways. Firstly, by drawing on ideas of relational space I will reconceptualise the work of eportfolios as being fundamental to the creation of a virtual landscape of ECEC between parents and teachers. In doing so I will illustrate how the technology can be viewed as an actor in this networked assemblage. Secondly, I will explore some of the power asymmetries expressed across this landscape, by considering the process of subjectification at work through the technology which serves to differently position actors. In so doing, I will caution that the creation of eportfolios and the unanticipated outcomes of the digitisation of new forms of data and knowledge has potentially profound implications for how the early education space is experienced and governed.

\section{Eportfolios and the Early Learning Environment}

This paper has been informed by empirical work which was conducted in New Zealand during 2014. Semi-structured interviews were carried out with two companies in NZ who provide an online platform for eportfolios. More specifically, I spoke in their place of work with company creators and some of the developers of the software who worked in those companies. One of the companies gave me access to a 'behind the scenes' look at their platform, to understand how managers and technicians view the software and the kind of information they can glean from it in addition to the primary communication function. In accordance with the ethical terms of the research, specific names of the companies and the interviewees have not been used. Images drawn on in this document have been adapted from promotional material, made publically available by the companies. In conducting the interviews, no specific eportfolios nor particular families were discussed. Instead I have drawn on my own observations and experiences of a mother of two young children, who are in an ECEC service which uses eportfolios to further inform my discussion.

\section{'Virtual' Landscape of Care between Parents and Teachers}

Thus far in the paper I have argued that the eportfolio technology can be seen as an important non-human constitutent of the relational space, 

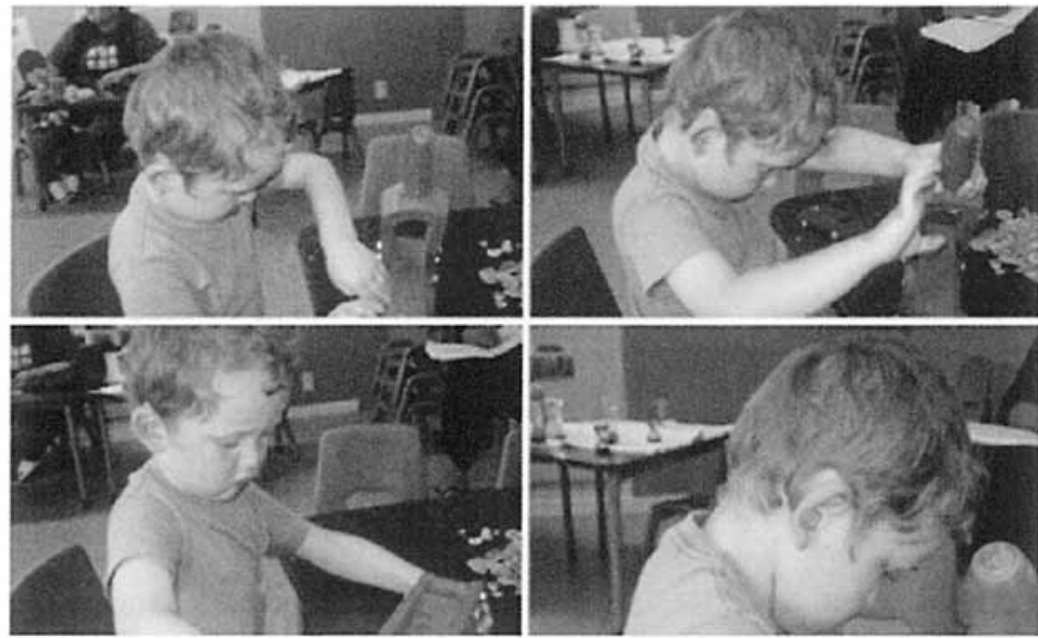

Following on from the wider group interest in the walnuts from our spex ial walnut tree. today 1 brought my nutcracker in for the children to use. Tom watched and showed so much curiosity as I demonstrated to a group of children how to use it. Tom was cager to have a turn and waited for the others...

Vew' more comenten:

旬.

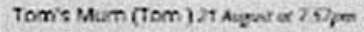

The is really grost that forn is learning how to take care of the new kids, be is reoly pidorig up on this behawour you teach so well at Storypark kids as we be seen him do the same thing at home when we ve had friends come rouns with irtio ones. And Tom I OVVES nuts - turpreed you got him to put any in the jot at all: Cool nutcrocker too.

fa)

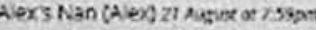

Thats nice to soe Mbx with Tom We wal hear all abeut the story of cradbing the nuts next time we see Alax.

(9).

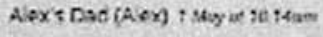

Figure 1: An example of a learning story and the eportfolio interface

which I have called the virtual landscape of ECEC. The emergent space is not discrete and bounded, into which technology is merely added. Rather the ECEC space should be seen as the product of the dynamic and multiple interrelationships between actors (human and non-human), knowledges, material objects and desires around the care and education of young children. The introduction of the eportfolio technology, as a non- human actor, profoundly alters the relational ECEC space in complex ways. In this section I will expand on this statement to explore just how the eportfiolo works to extend the relational space in order to enrol teachers, parents and wider family members.

One of the primary benefits of rendering learning stories into digital format, and of eportfolios more generally, has been the potential it has to 
bring family members closer to the learning experiences of their child(ren). In terms of how it works, learning stories are created by teachers (usually documented through a portable device) and then 'posted' via email to the child's parent(s). Under password protection, only people who have been approved to receive the stories (parents and grandparents for example) can access them. Speaking with the developers of the software, they have worked closely in conjunction with parents, teachers and children to ensure the software is customisable to the specific needs of the early education setting. As the creator of one company stated:

"It has to work for everyone involved. We work closely with teachers and conduct regular surveys to ensure that what we are providing to them is adaptable to their needs and is meeting their expectations. It needs to make the communication process easier, not be burdensome. So, we are really open to suggestions for new functions. To be honest that's how we get ideas for these developments. We aren't experts in teaching and pedagogy, that's not where our expertise lies. So we are pretty much reliant on the teachers and services to tell us what works and what doesn't". (Company A)

From speaking to the software developers, the platform is described like a living entity, one which is adapting and changing in close response to the needs of its parent and teacher users. By so doing it embeds itself centrally to the emergent relational network between teacher and parent.

In Figure 1 an example is given of a learning story and the eportfolio interface which is received by parents. In this example both parents of Alex and $\mathrm{Tom}^{6}$ received the message, and they in turn posted a response. As described in my opening narrative, parents are alerted to the creation of a learning story often when a message pops up on their computer or phone. In my case, and that of many parents who have their email open during the day on multiple devices, there is an immediacy to the alert which is important to the success of eportfolio technology. As one company creator suggested:

"Well we intended it to be something which will catch parents attention, so linked to their email account. Most parents have phones which are

6 Learning stories and eportfolios in general are held under password protection. The story of Tom and Alex was adapted from promotional material derived from the interviews conducted with one of the companies in the study. 
connected to the internet these days. It's something parents told us in our surveys that they liked, getting unexpected updates and images of their children while they were separated from them. The phone app was an add-on to be honest, to give people more options to access that information". (Company A)

Considering the agency of the technology at this point in shaping the virtual landscape of ECEC is important. Messages are being delivered asynchoronously, as its often a story which was recorded or documented at an earlier time, which the teacher wrote an accompanying narrative for and posted to family. The measure of the success of the technology is the extent to which parents engage with the portfolios in response to the learning stories. I suggest here it is successful in capturing parents attention (as the developer described it) through the use of affect in triggering a response in the parent recipient which encourages them to engage with the plaform. This positive affective response is stimulated via the use of images, recordings and other forms of documenting the childs experiences. While this was also the case with the paper based portfolios, I suggest that the manner in which the learning story is received (unexpectedly, to an electronic device and presented in a more engaging manner) heightens parents affective response. As described in the opening vignette, the very action of a message appearing in your email account (in my case popping up on screen) and the alert which can be activated to receive these messages creates a heightened anticipation of seeing your child at play and offers for most a welcome interruption. The traction of this technology is all the more potent, given the neoliberal working environment and the separation many parents feel during the working day.

The motivating idea behind the design of the platform for both companies who were interviewed is to facilitate ease of communication between parents and teachers and for greater connectedness to your childs learning experiences while in care.

"If your child makes its first step or some significant milestone, it's possible to capture that and relay it back to you on the day. It's very powerful to be able to capture that". (Developer, Company B)

The different ways of capturing the childs learning and development allows for a recognition that development is potentially physical, as much as cognitive (in terms of learning how to walk for example). Moreover, it is anticipated that members of the wider family can also be in contact with the 
child through documenting these experiences, and get to know them a bit better even though they may live on the other side of the world. This relay of information is crucial for the success of the network. Information from the parent about what the child enjoys doing at home in turn can be shared via the platform, in theory helping the teacher to design activities for them. Working from an ANT perspective, there is an extension of the relational network between home and ECEC service through the platform. This extension shapes how experiences of distance and proximity are felt and reworked. The virtual landscape of ECEC which is produced changes the spatio temporal experiences of the ECEC environment for users of the technology. The stories created are snapshots of childrens experiences already past. They may have only been of a short duration, before the child found some other more intriguing source of play (see Gallacher, 2006). However, they are used to extrapolate outwards as to the nature of the childs day. From my experience as a parent, learning stories tend to be only positive, leading to an assumption that learning only occurs from positive encounters where no tears are shed. Such is the bind of the ECEC teacher, whereby parents only want to see how contented their children are at all times, rather than the reality of life with a three year old, which tends to be more of a daily emotional rollercoaster.

The durability of the network is only maintained as long as the network speaks to the interests of all users and if they can find purpose in it as a result. Therefore it is only successful once the parents (all parents) use it. If it is not able to enroll parents to actively work through it, then it will not be sustainable. Convenience therefore is important. It cannot be a burdensome technology otherwise parental usage will be minimal. Consequently it must be able to manage messages from parents back to the teacher in multiple formats and as easily as possible (via recording or text or email generally). The developers innately understood this vulnerability in the technology, as it envisaged busy working parents and teachers as the users and therefore sought to widen the forms of engagement and communication (for example integrating recording functions for parental responses) to make it as amenable to parents, family and teachers as possible. This was an important part of the ongoing adaptation and development of the platform.

As a parent, once you delve into your childs learning story you may notice that it has been tagged or linked to different aspects of the curriculum (see Lee, Carr, Soutar, \& Mitchell, 2012), so parents can see what it relates to pedagogically and click on live links to inform themselves. Undoubtedly it is a significant development for parents to be better acquainted with the 
early years curriculum, not least as they can differently appreciate what their child is doing and how it speaks back to their broader development. To that extent it has an important function in shaping parental subjectivities, as 'informed' parents who can read their childs play and development in a different light. However, it is also important for teachers that parents have a better sense of what it is that they do as early years teachers. As one creator discussed

"Something which we developed later, through trialling the technology in services, was the links to the curriculum. Not all services do this, but it is an option we now provide. We are constantly looking to improve the software in keeping with the demands of teachers and parents...Yeah, we are always amazed at how innovative the ideas can be from teachers about what new design features to add to the platform. It keeps the software relevant and as useful as possible for teachers and their work with parents". (Developer, Company A)

In New Zealand, as is the case in many other countries internationally, ECEC teachers have to battle the continued devaluation of their work, despite its professionalization, as it is aligned with the care of young children and consequently is socially relegated as a glorified form of 'childminding' (Osgood, 2007). Allowing parents to see the pedagogical aspects of the work ECEC teachers do, by linking to the curriculum, potentially offers a powerful means of raising awareness of the professional practice of ECEC, with subsequent implications for how its viewed and practiced in society more generally. This is important for parents but also for teachers themselves, as it allows them to perform their professionalised identity as a teacher in a evident way. We can see then how not only parental identities are altered through engaging with the platform, but also those of teachers as well. Of course the question of subjectification is one which is associated with issues of power, and it is to this aspect of the virtual landscape of ECEC which I will now turn.

\section{Analytics, Power and Governing through the Network}

From the interviews conducted with the eportfolio companies, one of the most noticeable discourses was that of the technology being as "user-friendly' as possible. The reiteration of the online platform as being user friendly, shapes the terrain in which actors become involved with the technology and moreover creates expectations around its usage (and non-usage ). The extent that the ICT designers go to to allow learning stories to be captured, narrated and then relayed to family creates a perceived inevitability that the 

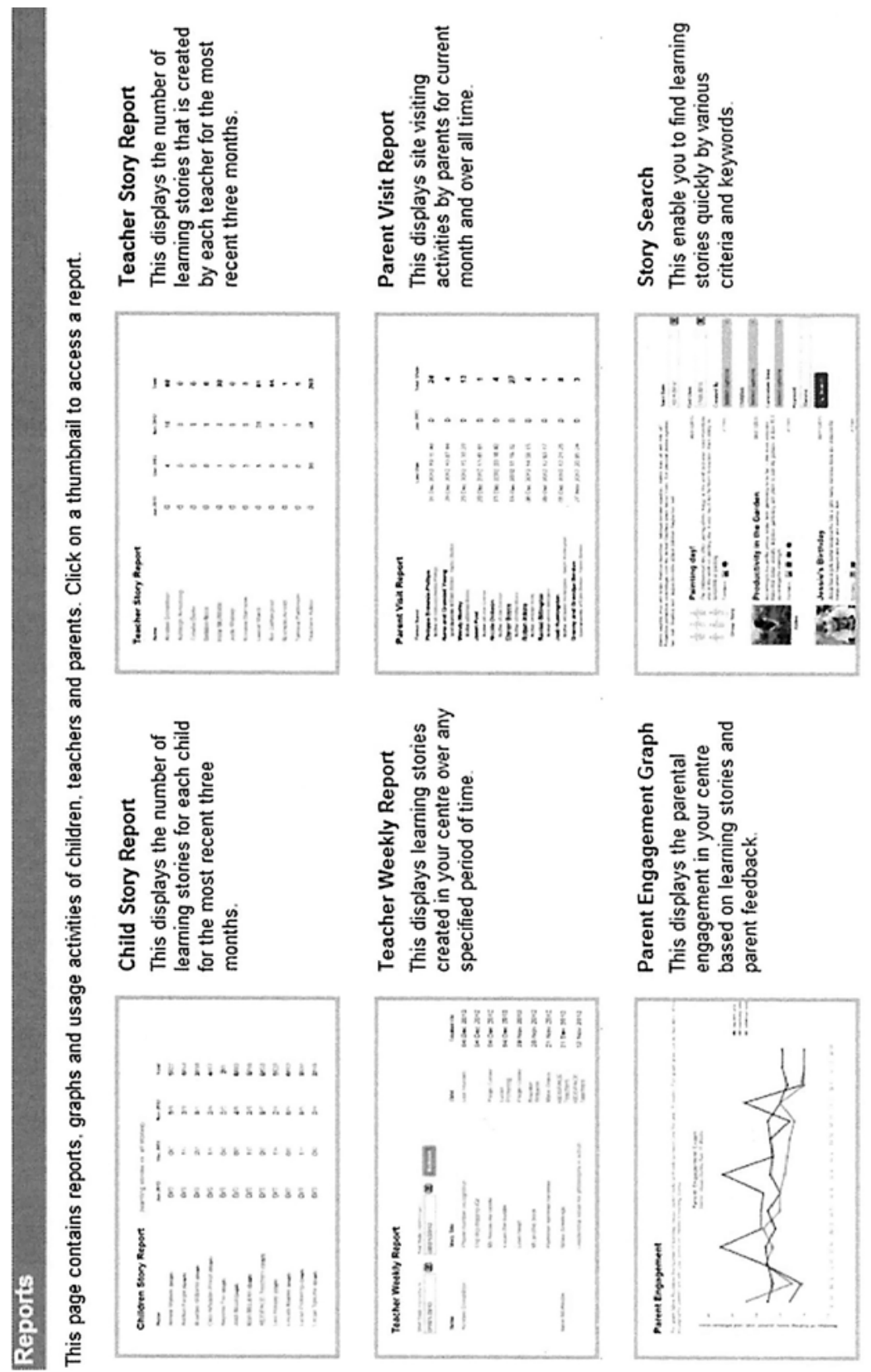

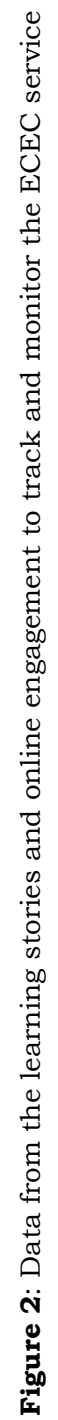


technology will be used by parents and teachers as prospective consumers. If parents or teachers are not engaging with the technology, then the problem must be with the user rather than the technology. Consequently non-usage or participation in the network can lead to negative perceptions, such as parental disinterest in a childs learning for example. From an ANT perspective, the strength of the network is based on aligning interests and goals of actors, such that involvement becomes almost inevitable, the new 'normal'. Participation then becomes either through consent or coercion. The platform thus shapes what we expect in terms of behavior of the actors involved, such that non participation with the technology undermines the network.

The platform, while having communication as a primary function, is also making visible the early education space in a way which was not before possible through the generation of new data. As Foucault convincingly argued, with knowledge comes power (Foucault, 1997). There are other unanticipated aspects of this online platform which have emerged after its initial introduction, stemming from the information which can now be gleaned from the eportfolios. One of these alternative uses has been the generation of new forms of visual data derived from the learning stories. This has manifested in a substantial analytics and reporting function now available as part of the platform. As Figure 2 shows, data can be derived from the learning stories and online engagement more generally to allow a manager or head office to better track and monitor the ECEC service. It does so through production of a range of graphs which capture aspects like: how many learning stories a teacher creates, how many stories for each child and so on. As the creator of one company suggested

"The report was initially developed to help the centres understand parents' engagement because it's really troubling for the centres having great documentation, great parental feedback on paper but it's really time consuming and difficult to demonstrate that. As times gone by we've built a lot more types of reports into the system. If you look at the reports that we've built they're mostly around giving the centre more visibility into how well the parents are engaging and documentation around their children's learning, curriculum and goals and the interests of children and discovering the common interests and continuity of particular learning. Those groups of reports were basically created because we want to help the centre to refine their planning and give them a greater control so they can provide an even higher quality programme for children to achieve a better outcome." (Company B) 
Engagement can be traced not only of parents (through the production of graphs showing the ebb and flow of parental views) but also of staff interaction with children. Importantly however, not everyone has equal access to such information. Rather, its part of a suite of functions available to ECEC manager, suggesting that information flows in the network are not equal. While parents receive learning stories from teachers, and can respond, much more information is gleaned about the nature of the participation from a managerial perspective than parents are perhaps aware of. From an ANT perspective, the network has been lengthened to take account of managerial concerns and to encompass the interests of managers alongside teachers and parents. The increase of governmental and self regulation in the ECEC environment (Osgood, 2006) offers a natural home for this data, as the above interviewee suggests it can be used to demonstrate good practice and strong levels of engagement between teachers and parents in instances of external practice review ${ }^{7}$.

Moreover, engagement with Te Whariki, the NZ bicultural curriculum, can be monitored as each story can be tagged or linked to an aspect of the curriculum. If a teacher or centre is consistently overlooking one key aspect of the curriculum, this can be identified through analysis of the learning stories. As was suggested

" $a$ third, more recent group of reports have been produced around helping centers support teachers, because teachers only have a very limited amount of non-contact time. You may have a junior teacher who is less experienced than others and so having the ability to uncover that information about how they are relating to the children and the curriculum is useful for the centre in order to provide greater support to that teacher". (Company B)

These new metrics give a sense of the unevenness within the emergent landscape of care and illustrate how asymmetries of power are being produced through the technology itself. The e-portfolios and broader data being derived from them, take on an active role in shaping the relationships between centre, teacher and parent. To that extent they are more than a benign technology. They occupy a central role in the virtual landscape of ECEC, as they have an impact on how others act in response. For example, a centre manager gains a different insight into the work of each teacher through their eportfolio data and may act accordingly. Moreover, teachers' perception of

$\overline{7}$ In NZ ECEC services are subject to review every three years or less by the Education Review Office. 
parents can be shaped by whether or not they actively engage with their children's learning stories and the extent to which they respond. As the data illustrates, there are inequities in how the reporting ocurrs, whether that is deliberate or not. The analytics function makes visible forms of exclusion in new ways (for example if a child is not getting as many stories created about them or if parental engagement is not as frequent as others). Consequently we can see how the technology allows for power to flow in particular ways through and across the network, positioning actors differently and producing forms of knowledge which shape our behaviour and expectations of one another.

\section{Discussion}

The significant growth of online portfolio technology marks an interesting shift in the constitution of the early education environment. As this technology gains significant traction in a highly competitive childcare market (Gallagher, 2017), I suggest that this is a pertinent juncture to reflect on the complex intended, and unintended outcomes for early education providers, teachers and parents. In so doing it is important to view it as much more than a simple communicative device, added into an existing set of ECEC relationships. As my interviews with creators and developers of the technology have illustrated, the platform is an ongoing, emergent space which is cocreated alongside parents, teachers and more recently managers. However, each of these actors are very differently positioned within the virtual landscape of ECEC which has emerged. Power is not equally distributed through the network, but rather flows and rests at particular points. Through ongoing adaptation of the platform it has morphed into something with much more functionality than originally intended, and in a way which positions it as increasingly fundamental to the running of the early education environment as a networked, relational space. ANT scholars have shown the success of any technological innovation is strongly wedded to how well it is embedded in the network of users. Once it loses utility and functionality, it becomes obsolete. Thus the ability of the platform to capture the diverse interests of those involved in the sector, to translate those interests, is crucial to its continued centrality in the emergent network.

As networks generate their own specific time-space configurations, they also produce variegated landscapes of engagement with connections of differing lengths and duration. Thus engagement through the platform flattens and reshapes our time-space understandings of the early education environment. It forges new temporalities and spatialities of education and care, 
with the ability to incorporate family from far away parts of the world. One of the significant changes eportfolio and online engagement more generally has brought to the fore is that it alters our understanding of distance and proximity to children's experiences. The platform invokes different experiences of closeness, which supersedes physical distance, and allows parents to feel part of their child's experiences although they are separated from them. It also has the potential to bring family members into proximity with their child or grandchilds' learning journey, even over asynchronous time zones. As I have suggested, this kind of development speaks more broadly to the distancing of parents during the working day from their children. As the political emphasis is increasingly placed on workforce activation in neoliberalised countries, like New Zealand (Kingfisher, 2013), the traction of interactive technologies like eportolios may represent an important development which addresses parental guilt ${ }^{8}$.

The virtual landscape of ECEC mediated through the technology relies on strong affective resonances with those receiving the learning stories. Building on the work by Milligan and Wiles around landscapes of care and the role of technology in mediating how we care for another, I suggest that the way the technology works to generate emotional, caring and affective responses is a crucial part in the performance of ECEC. The way the stories are mediated, the manner in which they are delivered and the kinds of insights they tend to capture, all seek to compel parents to want to engage with the platform. Making the technology as 'user-friendly' as possible suggests failure to engage as a mark on the user rather than the technology. Thus within this emergent virtual landscape of ECEC a potential question to be asked is whether there is space for parental and teacher non participation?

However, the platform can also be viewed as playing a central role in governing parents and teachers, and has the capacity to be a disciplinary tool in equal measure. As Latour suggests, its often the work of the non-human, such as technology, which stabilises the network, because as Murdoch suggests "technologies can make good disciplinary machines" (2006, p. 66). In an increasingly neoliberalised environment, where we are all expected to act as 'entrepreneurs of the self' (Lemke, 2002; Rose, 1990; Rose, O'Malley $\&$ Valverde, 2006), eportfolio technology has the potential to become a dis-

8 An alternative reading of this development of course is offered by advocates of the theory of 'paranoid parenting', which would position eportfolios as part of a suite of technologies which force parents to feel singularly responsible for every aspect of their child's life (what Furedi refers to as 'parental determinism'). (Furedi, 2008) 
ciplinary tool for all involved ${ }^{9}$. In relation to parents we can see the disciplinary potential at work in a number of ways. For example, the immediacy with which a new learning story is made known to parents urges you to engage with the technology. It invokes an affective response through the images and stories created about your child. It encourages both teacher and parents to engage and respond by making the interface as 'user friendly' as possible (even to the extent of recording a message rather than typing one out). Moreover, the production of graphs and other analytic material allows for a different reading of the relationships between teacher and parent and can shape how each participant in the network is viewed. To that extent teachers may adapt their behaviour, both in terms of their practices with the children (through having to link to the curriculum for example) and how they perceive the child's parent(s) and their engagement in response to the data produced. Teachers themselves may also be encouraged to reflect on how their teaching is seen at a managerial level, as read through the graphs. Thus there are new power asymmetries emerging in the ECEC setting as a result of some of the unanticipated uses derived from eportfolios. Rendering the relational work of teaching and caring for young children into digital form via the learning stories has made visible this work in new ways for management ${ }^{10}$. As illustrated, the production of new analytics to capture the relationship between teacher, child and parents offers potentially powerful means of governing and subjectifying individuals subjects. Consequently, I suggest that it is important to be cognisant of the potential disciplinary role of eportfolios in governing and shaping the behaviour of those involved in the network.

\section{Conclusion}

In keeping with the theme of this special issue, this paper has sought to highlight how geographical thinking, in particular some of the key ideas around relational space, can offer new insights into the role of eportfolios in the ECEC environment. Influenced by ANT, an approach which broadens our understandings of agency to incorporate a more than human lens, I have shown how the technology can be viewed as an agent in the relational network between managers, teacher, parents and wider family. What emerges is a co-created, virtual landscape of ECEC one which is mediated through the technology. Through the platform, traditional notions proxim-

9 See O’Brien, Osbaldiston \& Kendall (2014) for a comparable discussion of the role of eportfolios as a regulatory and disciplinary tool in higher education.

10 See Osgood (2006) for a critical discussion of regulation and managerialism in the early education environment. 
ity and distance are disrupted as parents are drawn closer to the learning experiences of their child. In this paper, I have argued that this development is all the more pertinent in light of broader political and economic policy ambitions in countries like New Zealand, where work force participation by mothers is increasingly an expectation rather than a choice and where more children than ever are in extra-familial care during the working day. However, questions can be asked as to what exactly is being documented through the eportfolio? It remains to be seen in what way are eportfolios for children rather than solely about children. Moreover, how representative is it of the childs day or is it cherrypicking positive aspects of their day and extrapolating outwards to generate a learning story for parental consumption? These are perhaps quite pessimistic questions to pose, given the large scale adoption and general endorsement of eportfolio technology, however I suggest that it is important to query at this juncture who the introduction of this technology is for and to what end.

The platform also performs other functions which have been developed as the interests of more users have been enrolled into the network. In this case, the data derived from the eportolio serves the needs of managers in understanding the relationships between teachers, parents and the children in new ways. As suggested, the graphs and analytics created can have a powerful effect on how participants are both viewed and addressed, and plays a role in shaping the behaviour of all involved to produce the 'good' teacher and the 'good' parent subjects. Thus, once parents and teachers are enrolled into using the technology, the platform can become a disciplinary tool which operates at a distance to shape practices and engagement of all involved. A second set of questions can be asked about how participation or non participation is being read by other actors in the network. With the production of a range of new analytics and the power now potentially derived from the knowledge they produce, are levels of engagement (frequency, expediency of reply of parents and so on) being viewed as a proxy for care within the emergent virtual landscape of ECEC?

Finally, while I have drawn on the theoretical insights of ANT in this paper, what I have offered here merely begins to open up some new ways of thinking about eportfolios in the ECEC environment. A more in-depth, comprehensive study would involve a longitudinal ethnographic methodology, which takes account of how the learning stories are generated and the experiences of children as well as adults in the creation of the portfolio. As proponents of ANT have suggested, the only way to truly understand a network and the relations being produced is to 'follow the actor'. In the case of 
eportfolios and the early education environment, this would involve a ethnographic approach which would seek to trace the connections, materials and the relationships between different materials in order to flesh out the network and to understand where power is held in that network. Empirically this approach would follow parent-users, teachers, managers and children, as they engage with the platform. As stressed in this paper, both the human and non-human should be taken into account as potential actors within the network, thereby not closing off the possibility of the technology to shape and stabilise network relations. Indeed this approach may offer an innovative means of exploring the role of ICT more generally in the early education environment, in so doing allowing for a more heterogenous understanding of ECEC and the relations and materials that make up this crucial resource for children and working families.

\section{Acknowledgment}

The author would like to acknowledge that funding for this research has been provided by the Royal Society of New Zealand, Marsden Fund. She would also like to thank Deborah Brennan for ongoing project support, and Sabine Bollig, Zsuzsa Millei and the anonymous referees for feedback on an earlier version of this paper.

\section{References}

Allen, J. (2011). Topological twists: Power's shifting geographies. Dialogues in Human Geography, 1(3), 283-298.

Blaiklock, K. (2008). A critique of the use of learning stories to assess the learning dispositions of young children. New Zealand Research in Early Childhood Education, 11, 77-87.

Beaumont-Bates, J. (2017). E-Portfolios: Supporting collaborative partnerships in an early childhood centre in Aotearoa/New Zealand. New Zealand Journal of Education Studies, 52, 347-362.

Crang, M., \& Thrift, N. (2000). Thinking space. London: Routledge.

Eldon, S. (2009) Space. In R. Kitchen, \& N. Thrift (Eds.), The International enclycopedia of human geography. London: Elsevier Publishing.

Foucault, M. (1977). Discipline and punish: The birth of the prison. London: Penguin. Foucault, M. (1997). Governmentality. In G. Burchell, C. Gordon, \& P. Miller (Eds.), The Foucault effect: Studies in governmentality (pp. 87-104). Chicago: Chicago University Press.

Furedi, F. (2008). Paranoid parenting: Why ignoring the experts may be best for your child. London: Continuum International Publishing Group Ltd.

Gallacher, L.A (2006). Making space for excess in the nursery? Or superheros in the doll corner. Paper presented at the Annual Conference of the Royal Geographi- 
cal Society with the Institute of British Geographers, London, 1st September 2006 accessed at https://www.researchgate.net/profile/Lesley_Gallacher/publication/228392989_Making_space_for_excess_in_the_nursery_Or_superheroes_in_ the_doll_corner/links/5759600208ae414b8e43b000.pdf

Gallagher, A. (Forthcoming). The business of care: Marketization and the new geographies of childcare. Progress in Human Geography, XX (X), 1-17.

Gallagher, A. (2017). Growing pains? Change in the New Zealand childcare market 2006-2016. New Zealand Geographer, 73(1), 15-24.

Goodman, M., \& Cherrington, S. (2015). Parent, Whanau and teacher engagement through online portfolios in early childhood education. Early Childhood Folio, 19(1), 11-16.

Harvey, D. (2006). Space as a keyword. In D. Gregory, \& N. Castree (Eds.), David Harvey: A Critical Reader. Malden: Blackwell.

Higgins, A., \& Cherrington, S. (2017). Whats the story? Exploring parent-teacher communication through ePortfolios. Australasian Journal of Early Education, 42(1), 13-21. Holloway, S. L., Hubbard, P., Jöns, H., \& Pimlott-Wilson, H. (2010). Geographies of education and the significance of children, youth and families. Progress in Human Geography, 34(5), 583-600.

Holloway, S. L., \& Valentine, G. (2001). 'It's only as stupid as you are': Children's and adults' negotiation of ICT competence at home and at school. Social \& Cultural Geography, 2(1), 25-42.

Jafari, A., \& Kaufman, C. (2006). The eportfolio handbook. London: Idea Group.

Kerckaert, S., Vanderlinde, R., \& van Braak, J. (2015). The role of ICT in early childhood education: Scale development and research on ICT use and influencing factors. European Early Childhood Education Research Journal, 23(2), 183-199.

Kingfisher, C. P. (2013). A policy travelogue: Tracing welfare reform in Aotearoa/ New Zealand and Canada. New York: Berghahn Books.

Latour, B. (2005). Reassembling the social: An introduction to actor network theory. Oxford: Clarendon.

Law, J. (2008). On sociology and STS. The Sociological Review, 56(4), 623-649.

Law, J., \& Hassard, J. (1999). Actor network theory and after. Oxford: Blackwell Publishing.

Lee, W., Carr, M., Soutar, B., \& Mitchell, B. (2012). Understanding the Te Whariki approach. London: Routledge.

Lemke, T. (2002). Foucault, governmentality and critique. Rethinking Marxism, 14(3), 49-64.

Lewis, J. (2001). The decline of the male breadwinner model: Implications for work and care. Social Politics, 8(2), 152-169.

Lewis, L. (2015). A critical reflection on eportfolio as a critical learning tool. New Zealand Journal of Teachers' Work, 12(2), 115-130.

MacLeavy, J. (2011). Reconfiguring work and welfare in the UK's 'New Economy': Regulatory geographies of welfare-to-work at the local level. Gender, Place \& Culture, 18(5), 611-633.

Marsden, S. A., Jones, J.P. II, \& Woodward, K. (2005). Human geography without scale. Progress in Human Geography, 30(4), 416-432.

Massey, D. (2005). For space. London: Sage Publications. 
McDowell, L. (2004). Work, workfare, work/life balance and an ethic of care. Progress in Human Geography, 28(2), 145-163.

Milligan, C., \& Wiles, J. (2010). Landscapes of care. Progress in Human Geography, 34(6), 736-754.

Mol, A., \& Law, J. (1994). Regions, networks and fluids: Anaemia and social topology. Social Studies of Science, 24(4), 641-671.

Murdoch, J. (2006). Post-structuralist geography. London: Sage Publications.

O'Brien, P., Osbaldiston, N., \& Kendall, G. (2014). Eportfolios and egovernment: From technology to the entrepreneurial self. Educational Philosophy and Theory, 46(3), 284-295.

OECD. (2014). Enrolment in childcare and pre-schools. Director of Employment, Labour and Social Affairs. Retrieved from www.oecd.org/social/family/database

Osgood, J. (2006). Deconstructing professionalism in early childhood education: Resisting the regulatory gaze. Contemporary Issues in Early Childhood, 7(1), 5-14.

Osgood, J. (2006). Professionalism and performativity: The feminist challenge facing early years practitioners. Early Years, 26(2), 187-199.

Penman, R. (2014). Eportfolios: Connecting parents, Whanau, and teachers in kindergarten communities. Early Education, 56, 10-13.

Plowman, L., \& Stephen, C. (2005). Children, play, and computers in pre-school education. British Journal of Educational Technology, 36(2), 145-157.

Rose, N. (1990). Governing the soul: The shaping of the private self. London: Routledge. Rose, N., O'Malley, P., \& Valverde, M. (2006). Governmentality. Annual Review of Law and Social Science, 2, 83-104.

Valentine, G., Holloway, S., \& Bingham, N. (2002). The digital generation?: Children, ICT and the everyday nature of social exclusion. Antipode, 34(2), 296-315.

Valentine, G., \& Holloway, S. L. (2002). Cyberkids? Exploring children's identities and social networks in on-line and off-line worlds. Annals of the Association of American Geographers, 92(2), 302-319.

\section{Author:}

Dr. Aisling Gallagher

Massey University

School of People, Environment and Planning, Palmerston North

Palmerston North

Private Bag 11222

New Zealand

E-mail: a.gallagher@massey.ac.nz 